

\section{DISCLAIMER}

This document was prepared as an account of work sponsored by an agency of the United States Government. Neither the United States Government nor the University of California nor any of their employees, makes any warranty, express or implied, or assumes any legal liability or responsibility for the accuracy, completeness, or usefulness of any information, apparatus, product, or process disclosed, or represents that its use would not infringe privately owned rights. Reference herein to any specific commercial products, process, or service by trade name, trademark, manufacturer, or otherwise, does not necessarily constitute or imply its endorsement, recommendation, or favoring by the United States Government or the University of California. The views and opinions of authors expressed herein do not necessarily state or reflect those of the United States Government or the University of California, and shall not be used for advertising or product endorsement purposes.

This is an informal report intended primarily for internal or limited external distribution. The opinions and conclusions stated are those of the author and may or may not be those of the Laboratory.

This report has been repoduced directly from the best available copy.

Available to DOE and DOE contractors from the Office of Scientific and Technical Information P.O. Box 62, Oak Ridge, TN 37831

Prices available from (615) 576-8401, FTS 626-8401

Available to the public from the

National Technical Information Service

U.S. Department of Commerce

5285 Port Royal Rd.,

Springfield, VA 22161 


\section{DISCLAIMER}

Portions of this document may be illegible in electronic image products. Images are produced from the best available original document. 


\title{
DOCUMENTATION OF THE AMIP MODELS ON THE WORLD WIDE WEB
}

\author{
Thomas J. Phillips \\ Program for Climate Model Diagnosis and Intercomparison \\ Lawrence Livermore National Laboratory Livermore, CA, USA
}

August 1995 


\begin{abstract}
Summary documentation of the numerics, dynamics, and physics of models participating in the Atmospheric Model Intercomparison Project (AMIP) is now available on the Internet's World Wide Web. This paper describes the principal attributes of the electronic model documentation and provides instructions on how to access it.
\end{abstract}




\section{Introduction}

The intercomparison of atmospheric general circulation model (AGCM) experiments of a similar type has become an increasingly popular methodology for assessing the strengths and weaknesses of climate simulations (e.g., Cess et al. 1990, Randall et al. 1992). In such endeavors, attempts to attribute differences among the simulations to specific model properties require, as a minimum prerequisite, the accurate and comprehensive documentation of these features.

Regrettably however, atmospheric model documentation typically is fragmentary and scattered across numerous publications. It is also often inaccurate, in the sense that the pace of model development and the proliferation of new model versions usually outstrip their recorded descriptions. More often than not, the detailed configuration of a model for a particular experiment also is undocumented. In addition, there may be much unevenness in the descriptions of different facets of models (e.g., the description of atmospheric dynamics often eclipses that of surface processes). This incompleteness usually is replicated in published results of an intercomparison experiment, in that participating models' features often are summarized only perfunctorily.

By the early 1990's, developments within the World Climate Research Programme (WCRP) set the stage for redressing this state of affairs. A notable example was the 1991 launching of the Atmospheric Model Intercomparison Project (AMIP), an ambitious effort to evaluate the performance of current AGCMs in simulating the climate of the decade 1979-1988 under common specification of ocean temperatures and radiative forcings (Gates 1992). The widespread participation of international modeling groups (Table 1a) and the unprecedented scope of model diagnosis within the AMIP (Table 1b) made it imperative to set new standards in model documentation, as well as in a host of other arenas relevant for model intercomparison. Crucial support by the U.S. Department of Energy (DOE) also made it possible for the Program for Climate Model Diagnosis and Intercomparison (PCMDI) to meaningfully address these tasks in the course of its coordination of the AMIP on behalf of the WCRP.

Initially, documentation of the AMIP models crystallized in the form of PCMDI Report No. 18 (Phillips 1994), an extensive summary of the numerics, dynamics, and physics of 30 participating models. The report's chief strength was that it centralized information on these models according to a common, and reasonably comprehensive 
Table 1a: A list of the AMIP modeling groups and their locations.

\begin{tabular}{|c|c|c|}
\hline Acronym & AMIP Group & Location \\
\hline BMRC & Bureau of Meteorology Research Centre & Melbourne, Australia \\
\hline$\overline{\mathrm{CCC}}$ & Canadian Centre for Climate Research & Victoria, Canada \\
\hline CCSR & Center for Climate System Research & Tokyo, Japan \\
\hline CNRM & Centre National de Recherches Météorologiques & Toulouse, France \\
\hline COLA & Center for Ocean-Land-Atmosphere Studies & Calverton, Maryland (USA) \\
\hline CSIRO & Commonwealth Scientific \& Industrial Research Organization & Mordialloc, Australia \\
\hline CSU & Colorado State University & Fort Collins, Colorado (USA) \\
\hline DERF & Dynamical Extended Range Forecasting (at GFDL) & Princeton, New Jersey (USA) \\
\hline DNM & $\begin{array}{l}\text { Department of Numerical Mathematics } \\
\text { (of the Russian Academy of Sciences) }\end{array}$ & Moscow, Russia \\
\hline ECMWW & European Centre for Medium-Range Weather Forecasts & Reading, England \\
\hline GFDL & Geophysical Fluid Dynamics Laboratory & Princeton, New Jersey (USA) \\
\hline GISS & Goddard Institute for Space Studies & New York, New York (USA) \\
\hline GLA & Goddard Laboratory for Atmospheres & Greenbelt, Maryland (USA) \\
\hline GSFC & Goddard Space Flight Center & Greenbelt, Maryland (USA) \\
\hline IAP & $\begin{array}{l}\text { Institute of Atmospheric Physics } \\
\text { (of the Chinese Academy of Sciences) }\end{array}$ & Beijing, China \\
\hline JMA & Japan Meteorological Agency & Tokyo, Japan \\
\hline LMD & Laboratoire de Météorologie Dynamique & Paris, France \\
\hline MGO & Main Geophysical Observatory & St. Petersburg, Russia \\
\hline MPI & Max Planck Institut fuer Meteorologie & Hamburg, Germany \\
\hline MRI & Meteorological Research Institute & Ibaraki-ken, Japan \\
\hline NCAR & National Center for Atmospheric Research & Boulder, Colorado (USA) \\
\hline NMC & National Meteorological Center & Suitland, Maryland (USA) \\
\hline NRL & Naval Research Laboratory & Monterey, California (USA) \\
\hline RPN & Recherche en Prévision Numérique & Dorval, Canada \\
\hline SUNYA & State University of New York at Albany & Albany, New York (USA) \\
\hline SUNYANCAR & $\begin{array}{l}\text { State University of New York at Albany/ } \\
\text { National Center for Atmospheric Research }\end{array}$ & $\begin{array}{l}\text { Albany, New York/ } \\
\text { Boulder, Colorado (USA) }\end{array}$ \\
\hline UCLA & University of California at Los Angeles & Los Angeles, California (USA) \\
\hline UGAMP & $\begin{array}{l}\text { The UK Universities' Global Atmospheric Modelling } \\
\text { Programme }\end{array}$ & Reading, England \\
\hline UIUC & University of Illinois at Urbana-Champaign & Urbana, Illinois (USA) \\
\hline UKMO & United Kingdom Meteorological Office & Bracknell, United Kingdom \\
\hline YONU & Yonsei University & Seoul, Korea \\
\hline
\end{tabular}


Table 1b: A list of the AMIP diagnostic subprojects and their scientific foci. (Coordination with other World Climate Research Programme initiatives is noted as appropriate.)

\begin{tabular}{|c|c|}
\hline Subproject & Scientific Focus \\
\hline 1 & Variability of the tropics: synoptic to intraseasonal time scales \\
\hline 2 & Intercomparison of low frequency variability \\
\hline 3 & Cyclone frequencies and extratropical intraseasonal variability \\
\hline 4 & Clear-sky greenhouse sensitivity, water vapor distribution, and cloud radiative forcing \\
\hline 5 & Surface boundary fluxes over the oceans \\
\hline 6 & Monsoons (coordinated with MONEG/TOGA,WGNE) \\
\hline 7 & Intercomparison of hydrologic processes in general circulation models \\
\hline 8 & Polar phenomena and sea ice (coordinated with SIOMP/ACSYS) \\
\hline 9 & Validation of high latitude tropospheric circulation in the Southern Hemisphere \\
\hline 10 & Diagnostics of atmospheric blocking in general circulation models \\
\hline 11 & Validation of humidity, moisture fluxes, and soil moisture in general circulation models \\
\hline 12 & Land surface processes \& parameterizations (coordinated with PILPS/GCIP/GEWEX,WGNE) \\
\hline 13 & Diagnoses of global cloudiness variations in model results and observational data \\
\hline 14 & Cloud radiative forcing: intercomparison and validation \\
\hline 15 & Atmospheric angular momentum fluctuations in global numerical models \\
\hline 16 & Simulations of the stratospheric circulation \\
\hline 17 & Multi-scale water and energy balance processes (coordinated with GCIP/GEWEX) \\
\hline 18 & Capability of current models to simulate extreme events and associated circulation patterns \\
\hline 19 & Model validation by microwave sounding unit (MSU) data \\
\hline 20 & Intercomparison of model simulated circulation features related to Southern Africa \\
\hline 21 & Surface monthly and daily time-scale climatologies and regional climate anomalies \\
\hline 22 & Comparative energetics analysis of climate models in the wavenumber domain \\
\hline 23 & Variations of the centers of action \\
\hline 24 & Analysis of Caspian Sea regional climate data as compared to AMIP model outputs \\
\hline 25 & General circulation model simulation of the East Asian climate \\
\hline 26 & Monsoon simulation in the AMIP models \\
\hline
\end{tabular}

ACSYS: Arctic Climate System Study

GCIP: GEWEX Continental-Scale International Project

GEWEX: Global Energy and Water Cycle Experiment

MONEG: Monsoon Numerical Experimentation Group

PILPS:Project for Intercomparison of Land-Surface Parameterization Schemes

SIOMP: Sea Ice and Ocean Modelling Panel

TOGA: Tropical Ocean-Global Atmosphere

WGNE: Working Group on Numerical Experimentation 
framework (Table 2a). The bulk of the report qualitatively summarized the representation of these features in each AMIP model; tables also elucidated the ways in which selected properties played out across the models (Table $2 \mathrm{~b}$ ).

Despite the impressive scope of PCMDI Report No. 18, it suffered from an inherent limitation, in that the printed page is not well suited for the frequent updating of information that is endemic to the AMIP models. For example, since the 1994 publication of the report, the Center for Climate Systems Research has entered its model in the AMIP (Table 1a), and 8 groups have repeated the intercomparison experiment with new model versions.

Such frequent changes make it impractical to repeatedly issue printed revisions. The obvious need for a "living document" therefore demands the use of an electronic medium for rapid amendment and widespread dissemination of model documentation. While, in principle, this could be effected by physical transfer of archival media to AMIP participants (e.g., magnetic diskette or optical compact disk), the Internet's World Wide Web offers a much less costly means for transferring information, and in "real time" as well.

\section{The World Wide Web}

For some years, scientists have exchanged information on the Internet, e.g., via electronic mail and newsgroups, the File Transfer Protocol (FTP), and the Gopher and Wide Area Interactive System (WAIS) Protocols. However, the recent emergence of the World Wide Web, based on the Hypertext Transfer Protocol (HTTP), has qualitatively transformed the relationship of scientists to the Internet (Berners-Lee et al. 1994).

Since the inception of the World Wide Web (WWW, or W3) only a few years ago, the application of this technology has grown exponentially (from less than 100 Web sites in 1993 to about 35, 000 by mid-1995). In part, this growth is due to a server-client protocol that reprises the interaction exemplified originally by anonymous FTP: information is served automatically "on demand" to each client. However, the phenomenal popularity of the Web is due mostly to its support of multimedia applications (text, images, sound) which can be accessed "seamlessly" across different computing platforms. The scientific utility of these capabilities is apparent. (Indeed, the World Wide Web was created at CERN, the European Laboratory for Particle Physics, in order to foster collaborative exchange of scientific information in a variety of forms--see Segal 1995.) 
Table 2a: A list of feature categories considered in the AMIP model summary documentation. The representation of these features is summarized for each AMIP model.

- AMIP representative(s)

- Model designation (following the WGNE-recommended form: institution, model and version, horizontal/vertical resolution)

- Model lineage (predecessor and related models)

- Model documentation (key references)

- Horizontal representation (spectral or finite differences)

- Horizontal resolution

- Vertical domain (lowest/highest atmospheric levels)

- Vertical representation (coordinates and differencing schemes)

- Vertical resolution

- Computer/operating system (for the AMIP simulation)

- Computational performance (minutes per simulated day)

- Initialization (of atmospheric state, snow cover/depth, and soil moisture)

- Time integration scheme(s)

- Smoothing/filling (types of algorithms used)

- Sampling frequency (AMIP history storage interval)

- Atmospheric dynamics (state variables)

- Diffusion (horizontal and vertical)

- Gravity-wave drag

- Solar constant/cycles (AMIP solar constant, inclusion of diurnal cycle)

- Chemistry (radiatively active gases and aerosols)

- Radiation (shortwave/longwave schemes, cloud-radiative interactions)

- Convection (deep and shallow)

- Cloud formation (prognostic or diagnostic schemes)

- Precipitation (formation and subsequent evaporation)

- Planetary boundary layer (representation and depth)

- Orography (datasets, smoothing procedures)

- Ocean (treatment for AMIP simulation)

- Sea ice (treatment for AMIP simulation)

- Snow cover (formation/melting, effects on surface characteristics)

- Surface characteristics (surface types, roughness, albedo, emissivity)

- Surface fluxes (momentum, heat, and moisture)

- Land surface processes (vegetation and soil thermodynamics/hydrology) 
Table 2b: List of 15 feature tables included in the AMIP model summary documentation. The table entries consist of concise descriptors of the expression of the feature across all the AMIP models.

1. Model representation/resolution

2. Computational information

3. Initialization

4. Time integration

5. Filtering, smoothing, and filling

6. Diffusion and gravity-wave drag

7. Atmospheric chemistry

8. Atmospheric radiation

9. Cloud-radiative interactions

10. Convection

11. Cloud formation and precipitation

12. Planetary boundary layer

13. Snow cover and sea ice

14. Surface characteristics

15. Land surface processes 
Exchange of multimedia is made possible by the Web's lingua franca, the Hypertext Markup Language (HTML). "Hypertext" is a means of conveying electronic information by first fragmenting it, and then spanning the fragments by "hyperlinks" that are activated by "point-and-click" operations. A body of information therefore can be explored "nonlinearly", according to the user's whims (Nelson 1981, Schneiderman and Kearsley 1989). In HTML, the hyperlinks may span different media (e.g., text and images) as well as different servers (hence the term "World Wide Web"). For HTML multimedia to be rendered intelligible, however, one needs to use a W3 navigation tool (see Appendix).

\section{Hypertext Model Documentation}

Hypertext formatting greatly enhances the utility of lengthy treatises such as PCMDI Report No. 18, and atmospheric model documentation lends itself readily to this representation (Phillips and Meyer 1990). That is, because the individual scientist often has a particular interest only in a subset of models and properties, it is natural to break the hypertext documentation according to model (Table 1a), with provision for rapid access of all feature descriptions (Table $2 a$ ).

For the AMIP models, this schema is implemented by lists of hyperlinks that map the features of Table $2 a$ to each model in Table 1a (Phillips et al. 1995a). In addition, hyperlinks provide convenient cross referencing of related features within each model summary (see Display below). Moreover, each citation of a reference from the model documentation literature is connected to the associated bibliographic information by means of a hyperlink. The latter feature is essential for those scientists requiring quantitative details on model algorithms and parameterizations--information that is beyond the intended scope of the hypertext documentation. (A bibliography of references specific to each AMIP model is provided in addition to a comprehensive listing of more than 500 references. )

As in PCMDI Report No. 18, tables provide an overview of selected properties expressed across the AMIP models. A "History of Changes" page lists each update of the AMIP model documentation and a "What's New?" page advertises the most recent changes. In addition, a glossary explicates the many acronyms of the AGCM world, while hyperlinks connect to the Internet servers of these institutions.

Aside from the enhancements afforded by hypertext formatting, there are other 
significant advantages to accessing AMIP model documentation on the World Wide Web. For example, W3 browsers allow one to search on key words, and to save, annotate, and print HTML documents at the home site.

Display: Excerpted summary documentation of the representations of precipitation and planetary boundary layer in the AMIP version of the NCAR CCM2 model. Note usage of hyperlinks to cross reference related summaries of convection, diffusion, and surface fluxes in the model (indicated by underlined text) as well as bibliographic information on cited references (indicated by bracketed numerical footnotes).

\section{Precipitation}

Subgrid-scale precipitation is generated in unstable conditions by the moist convective scheme (see Convection). Grid-scale precipitation forms as a result of supersaturation under stable conditions. In this case, the moisture is adjusted so that the layer is just saturated, with the excess condensing as precipitation; the layer temperature is adjusted according to the associated latent heat release. (Moisture and temperature are mutually adjusted in two iterations.) Subsequent evaporation of falling precipitation is not simulated. Cf. Hack et al. (1993) [3] for details.

\section{Planetary Boundary Layer}

The PBL height is determined by iteration at each 20 -minute time step following the formulation of Troen and Mahrt (1986) [26]; the height is a function of the critical bulk Richardson number for the PBL, $u-v$ winds and virtual temperature at the PBL top, and the 10-meter virtual temperature, which is calculated from the temperature and moisture of the surface and of the lowest atmospheric level (at sigma $=0.992$ ) following Geleyn (1988) [27]. Within the PBL, there is nonlocal diffusion of heat and moisture after Holtslag and Boville (1993) [9]; otherwise (and under all conditions for momentum), properties are mixed by the stability-dependent local diffusion that applies in the model's free atmosphere. See also Diffusion and Surface Fluxes. 


\section{Future Plans}

In only a few years, the advent of the World Wide Web has revolutionized the manner in which much scientific information is exchanged. In the future therefore, PCMDI plans to vigorously apply this new technology in order to further the validation, intercomparison, and improvement of global climate models.

Having pioneered in developing hypertext AGCM documentation, PCMDI will maintain its currency for the AMIP. Feature descriptions of each new model version will be made available on the Web, as the requisite output data (Gates 1992) are quality assured and archived. Moreover, each model version will be identified unambiguously, as recommended by the WCRP's Working Group on Numerical Experimentation (see "Model Designation" in Table 2a), and will be situated historically in relation to other models (see "Model Lineage" in Table 2a). This documentation therefore will serve as an ongoing record of international AGCM development in coming years.

In the longer term, PCMDI plans to document the properties of coupled oceanatmosphere models that will increasingly become the focus of future intercomparison experiments. This will require development of new features categories (analogous to Table 2a) that are relevant for coupled models. The resulting summary descriptions of model properties also will be made available on the Web.

Finally, PCMDI intends to expand its other W3 applications that presently exist in embryonic form (Phillips 1995, Phillips et al. 1995b). These include W3 dissemination of PCMDI software, observational data products for model validation, and publications describing the activities of the PCMDI staff. In addition, information on AMIP participants, datasets, and publications will be appropriately updated with the further progress of this intercomparison project.

Questions or comments on PCMDI's World Wide Web pages are welcome, and may be directed to the author at phillips@tworks.llnl.gov.

Acknowledgments. I am indebted to Rita Anderson and Michael Brösius for diligently translating PCMDI Report No. 18 into HTML. I also gratefully acknowledge the assistance of representatives of the AMIP modeling groups in the correction and clarification of the documentation. This work was performed under the auspices of the U.S. Department of Energy, Environmental Sciences Division at the Lawrence Livermore National Laboratory (LLNL) under Contract W-7405-ENG-48. 


\section{References}

Berners-Lee, T., R. Cailliau, A. Juotonen, H. Frystyk Nielsen, and A. Secret, 1994: The World Wide Web. Communicns. Assoc. Comput. Machin., 37, 76-82.

Cess, R.D, G.L. Potter, J.P. Blanchet, G.J. Boer, A.D. DelGenio, M. Deque, V. Dymnikov, V. Galin, W.L. Gates, S.J. Ghan, J.T. Kiehl, A.A. Lacis, H. Le Treut, Z.-X. Li, X.-Z. Liang, B.J. McAvaney, V.P. Meleshko, J.F.B. Mitchell, J.-J. Morcrette, D.A. Randall, L. Rikus, E. Roeckner, J.F. Royer, U. Schlese, D.A. Sheinin, A. Slingo, A.P. Sokolov, K.E. Taylor, W.M. Washington, R.T. Wetherald, I. Yagai and M.-H. Zhang, 1990: Intercomparison and interpretation of climate feedback processes in 19 atmospheric general circulation models. J. Geophys. Res., 95, 16601-16615.

Gates, W.L., 1993: AMIP: the Atmospheric Model Intercomparison Project. Bull. Amer. Meteor. Soc., 73, 1962-1970.

Nelson, T., 1981: Literary Machines. Self-published, Swarthmore, PA.

Phillips, T. J., 1994: A summary documentation of the AMIP models. PCMDI Report No. 18, UCRL-ID-116384, Lawrence Livermore National Laboratory, Livermore, $\mathrm{CA}, 343 \mathrm{pp}$.

Phillips, T.J., 1995: AMIP information on the World Wide Web. In the Proceedings of the First AMIP Scientific Conference, 15-19 May, 1995, Monterey, California.

Phillips, T.J., and M.K. Meyer, 1990: A computerized database for general circulation model intercomparison studies. UCRL-JC-106079, Lawrence Livermore National Laboratory, Livermore, CA.

Phillips, T.J., R. Anderson, and M. Brösius, 1995: Hypertext summary documentation of the AMIP models. UCRL-MI-116384, Lawrence Livermore National Laboratory, Livermore, CA (URL http:/www-pcmdi.llnl.gov/phillips/modldoc/ amip/amip.html). 
Phillips, T.J., L.C. Corsetti, R. S. Drach, P. J. Gleckler, and S.M. Peterson, 1995: PCMDI World Wide Web pages. UCRL-MI-119847, Lawrence Livermore National Laboratory, Livermore, CA (URL http:/www-pcmdi.llnl.gov/).

Randall, D. A., R. D. Cess, J. P. Blanchet, G. Boer, A. D. DelGenio, M. Deque, V. Dymnikov, V. Galin, W. L. Gates, S. J. Ghan, J. T. Kiehl, A. A. Lacis, H. Le Treut, Z.X. Li, X.-S. Liang, B. J. McAvaney, V. P. Meleshko, J. F. B. Mitchell, J. J. Morcrette, G. L. Potter, L. Rikus, E. Roeckner, J. F. Royer, U. Schlese, D. A. Sheinin, A. Slingo, A. P. Sokolov, K. E. Taylor, W. M. Washington, R. T. Wetherald, I. Yagai and M.H. Zhang, 1992: Intercomparison and interpretation of surface energy fluxes in atmospheric general circulation models., J. Geophys. Res., 97, 3711-3724

Schneiderman, B. and G. Kearsley, 1989: Hypertext Hands-on! An Introduction to a New Way of Organizing and Accessing Information. Addison-Wesley, Reading, MA.

Segal, B.M., 1995: A short history of Internet protocols at CERN. Available on the World Wide Web (URL http:/wwwcn.cern.ch/pdp/ns/ben/TCPHIST.html). 


\section{Appendix: Accessing AMIP Information on the World-Wide Web}

\section{a. Internet Addressing Conventions}

To access information on the World Wide Web (W3), the essential first step is to obtain a connection to the Internet, either directly or through an Internet host computer, online service provider, etc.).

Each W3 server on the Internet has an associated address known as a Uniform Resource Locator (URL), which takes the form

\section{http://server_name/}

Here the string 'http' denotes the Hypertext Transfer Protocol. Every file on a W3 server is accessed according to a URL that is relative to that of the server's, e.g.

\section{http:/server_name/file_name.html}

where the extension 'html' identifies the file as one containing information expressed in the Hypertext Markup Language (HTML), the medium of exchange on the Web. The "home page" of a W3 server is a file that functions as a directory to other server files. (Access of the home page sometimes requires specification of a URL that includes its file name, but often the system is configured so that access of the W3 server alone is sufficient to bring up the home page.)

\section{b. Navigation Tools}

To operate on the Web, it is necessary to acquire a navigation tool, or "browser", that interprets documents written in HTML. A multitude of such browsers are presently available. Among these are the the Mosaic browser, whose development by the National Center for Supercomputing Applications (NCSA) sparked much of the early interest in the Web. Because it offers some additional enhancements, the Netscape Navigator (developed by the Netscape Communications Corporation) is now also very popular. Both Mosaic and Netscape browsers are available for use on X Window (Unix), Apple Macintosh, and Microsoft Windows computing platforms. These browsers also come with "viewers" and "players" for rendering images and audio applications. Users of computers that do not support multimedia may acquire a text-only browser such as Lynx, which currently runs in Unix, VMS, or DOS operating systems. A catalogue of other possible choices of navigation tools can be accessed from the home page of the World Wide Web (see Section $d$ ). 
Mosaic and Lynx browsers are freely available for nonprofit applications, and an unsupported (beta) version of Netscape Navigator also can be acquired for free (the supported version being available at nominal cost). All these browsers may be downloaded via anonymous FTP, and Mosaic and Netscape browsers can be obtained on diskette as well.

Most browsers come with "help" documentation to orient the new user to basic procedures (e.g., how to "open" a URL, navigate the Web, save and print W3 files, etc.). The W3 home pages for NCSA and Netscape also provide general information on the World Wide Web and the Hypertext Markup Language, as well as directories and "search engines" that can be used to identify URLs of interest. Much useful information of a similar type may also be obtained from the home page of the World Wide Web (see Section $d$ ).

\section{c. Accessing PCMDI's W3 Pages}

Once in possession of a W3 browser, a user can access the PCMDI home page at URL

\section{http://www-pemdi.llnl.gov/}

The home page contains a directory of hyperlinks (indicated by highlighted entries); clicking on these will pull up other PCMDI Web pages containing information, software, or data pertinent to climate modeling. For example, clicking on entries labeled "Model Features Documentation" will bring up the hypertext documentation of AMIP model features. This also can be accesed directly by opening URL

\section{http://www-pcmdi.llnl.gov/phillips/modldoc/amip.html}

Entries to other information on the AMIP (Phillips 1995) are provided on the PCMDI home page, or these can be accessed at URL

\section{http:/www-pcmdi.llnl.gov/phillips/AMIP.html}

\section{d. Address Information}

Addresses and FTP/W3 servers where the Mosaic, Netscape, and Lynx W3 browsers may be obtained are listed below. The URLs of relevant pages on the World Wide Web's home server are included as well. 
National Center for Supercomputing Applications (NCSA Mosaic)

The University of Illinois at Urbana-Champaign

605 E. Springfield, Champaign IL 61820

e-mail: mosaic@ncsa.uiuc.edu

Anonymous FTP: ftp.ncsa.uiuc.edu/Mosaic (use subdirectories/Unix, /Mac, or /Windows according to computing platform; see 'readme' files for installation directions.)

W3 URL: http://www.ncsa.uiuc.edu/General/NCSAHome.html

Netscape Communications Corporation (Netscape Navigator)

501 E. Middlefield Road, Mountain View, CA 94043

e-mail: info@netscape.com

Anonymous FTP: ftp.netscape.com/pub/netscape (Use subdirectories /unix, / mac, or /windows according to computing platform; see 'readme' files for installation directions.)

W3 URL: http:/www.netscape.com

Lynx (text-only W3 browser)

c/o Academic Computing Services

The University of Kansas

Lawrence, KS 66045

e-mail: lynxhelp@stat1.cc.ukans.edu

Anonymous FTP: ftp2.cc.ukans.edu/pub/hynx (Use subdirectories /ynx for Unix and VMS computing platforms and /DosLynx for DOS platforms; see 'readme' files for installation directions.)

W3 URL of Lynx Users Guide:

http://www.cc.ukans.edu/lynx_help/Lynx_users_guide.html\#TOC

\section{The World Wide Web Server}

W3 URL of home page : http:/www.w3.org/hypertext/WWW/TheProject.html

W3 URL of catalogue on client (browser) software for Web navigation:

http://www.w3.org/hypertext/WWW/Clents.html 


\section{PCMDI REPORTS}

Number

Title

Author(s)

Date

1 The Validation of Atmospheric Model

W.L. Gates

March 1992

2 Analysis of the Temporal Behavior of

J.M. Slingo

April 1992 Tropical Convection in the ECMWF Model

K.R. Sperber

J.-J. Morcrette

G.L. Potter

3 The Effect of Horizontal Resolution of Ocean Surface Heat Fluxes in the ECMWF Model

P.J. Gleckler

July 1992

K.E. Taylor

C. Covey

August 1992

$4 \quad$ Behavior of an Ocean General

Circulation Model at Four

Different Horizontal Resolutions

5 The Effects of Sampling Frequency on the Climate Statistics of the ECMWF General Circulation Model

6 Sensitivity of Dynamical Quantities to

J.S. Boyle

October 1992 Horizontal Resolution in a Climate Simulation with the ECMWF Atmospheric General Circulation Model (Cycle 33)

7 AMIP: The Atmospheric Model Intercomparison Project

T.J. Phillips

September 1992

K. Arpe

W.L. Gates

December 1992

8 The Impact of Horizontal Resolution

T.J. Phillips

January 1993 on Moist Processes in the ECMWF Model

L.C. Corsetti

S.L. Grotch 
9 A Modeling Perspective on Cloud Radiative Forcing

G.L. Potter

J.M. Slingo

February 1993

J.-J. Morcrette

L. Corsetti

10 The Use of General Circulation

B.D. Santer

March 1993

Models in Detecting Climate

U. Cubasch

Change Induced by Greenhouse

Gases

U. Mikolajewicz

G. Hegerl

11 Preliminary Validation of the Low Frequency Variability of Tropospheric Temperature and Circulation Simulated for the AMIP by the ECMWF Model

12 Simulation of the Indian and EastAsian Summer Monsoon in the

K.R. Sperber

November 1993 ECMWF Model: Sensitivity to Horizontal Resolution

S. Hameed

G.L. Potter

J.S. Boyle

April 1993

J.S. Boyle

November 1993

S.K. Sengupta

November 1993

J.S. Boyle Climate Models: A Common Principal Component Approach

14 Ocean Variability and its Influence on the Detectability of Greenhouse Warming Signals
B.D. Santer
U. Mikolajewicz
W. Brüggemann
U. Cubasch
K. Hasselmann
H. Höck
E. Maier-Reimer
T.M.L. Wigley

January 1994 
15 Cloud-Radiative Effects on Implied Oceanic Energy Transports as Simulated by Atmospheric General Circulation Models
16 DRS User's guide

17 The PCMDI Visualization and

Computation System (VCS): A

Workbench for Climate Data

Display and Analysis

18 A Summary Documentation of the AMIP Models

19 Global Ocean Circulation and Equator-Pole Heat Transport as a Function of Ocean GCM Resolution

20 The Northern Wintertime Divergence Extreme at $200 \mathrm{hPa}$ and Surface Cyclones as Simulated in the AMIP Integration of the ECMWF General Circulation Model
P.J. Gleckler

March 1994

D.A. Randall

G. Boer

R. Colman

M. Dix

V. Galin

M. Helfand

J. Kiehl

A. Kitoh

W. Lau

X.-Z. Liang

V. Lykossov

B. McAvaney

K. Miyakoda

S. Planton

R. Drach

R. Mobley

D.N. Williams

R.L. Mobley

March 1994

T.J. Phillips

April 1994

C. Covey

June 1994

March 1994

Aprill 1994

June 1994

J.S. Boyle

November 1994 
21 Towards the Detection and

B.D. Santer

January 1995

Attribution of an Anthropogenic

Effect on Climate

K.E. Taylor

T.M.L. Wigley

J.E. Penner

P.D. Jones

U. Cubasch

22 The Effect of Horizontal Resolution

G.L. Potter

July 1995 on Cloud Radiative Forcing in the ECMWF Model

23 Intercomparison of the Spectral

J.S. Boyle

July 1995

Characteristics of $200 \mathrm{hPa}$ Kinetic Energy in Some AMIP Simulations 